\title{
Board monitoring efficiency and the value of conservative accounting
}

\author{
Yanmin Gao ${ }^{1}$ Alfred Wagenhofer ${ }^{2}$ (I)
}

Published online: 18 August 2020

(C) The Author(s) 2020

\begin{abstract}
This paper provides a theoretical explanation for the observation that firms with strong corporate governance exhibit more conservative accounting. We study one of a board's most important decisions: to retain or replace the incumbent manager. The board uses accounting information and additional information from costly board monitoring. We show that if the accounting information is useful only for the replacement decision, then conservatism is harmful because it leads to too much replacement. If accounting information is relevant for the board's decision whether to monitor, then conservatism is beneficial when the board is a sufficiently efficient monitor. We also provide several predictions for empirical tests.
\end{abstract}

Keywords Conservative accounting · Corporate governance $\cdot$ Board of directors · Board monitoring $\cdot$ Management replacement

JEL Classification M41 · G34 · D82

\section{Introduction}

Accounting information plays a major role in corporate governance. It decreases uncertainty and asymmetric information and supports other corporate governance mechanisms. In particular, boards of directors crucially depend on accounting information to discharge their responsibilities. This paper studies one of the most important responsibilities: the decision to retain or replace an incumbent manager (Larcker and Tayan 2016). To support this decision, the board uses accounting

Alfred Wagenhofer

alfred.wagenhofer@uni-graz.at

Yanmin Gao

ygao@tru.ca

1 Thompson Rivers University, 805 TRU Way, Kamloops, BC V2C 0C8, Canada

2 University of Graz, Universitaetsstrasse 15, 8010 Graz, Austria 
information directly and can, depending on that information, produce additional information about the manager in its monitoring role. Our paper shows that conservative accounting is more desirable if the board is more efficient in obtaining such additional information.

Conservatism is a key characteristic of accounting systems. ${ }^{1}$ Broadly, it means that, under uncertainty, assets and income should not be overstated and liabilities and losses should not be understated. Thus, conservatism introduces a downward bias, which conflicts with providing neutral information. There has been much prior research to better understand whether, and why, conservatism is desirable, considering a wide set of uses of accounting information. In this paper, we study conservative accounting in a corporate governance context.

Empirical research generally finds that stronger corporate governance, including more effective boards, more independent boards, or boards with more outsiders, are associated with more conservative accounting practices (Beekes et al. 2004; Lobo and Zhou 2006; Ahmed and Duellman 2007; García Lara et al. 2007, 2009; Ramalingegowda and Yu 2012). For example, García Lara et al. (2009) provide evidence consistent with stronger corporate governance causing more conservative accounting, suggesting that conservatism enhances the effectiveness of corporate governance. Other papers find no strong relation between strength of governance and conservatism (e.g., Larcker et al. 2007; Krishnan and Visvanathan 2008). ${ }^{2}$ Empirical studies are often not powerful enough to identify, or distinguish between, reasons why conservatism is, or is not, beneficial in a particular situation. Especially in such situations, theory can help to improve our understanding of the underlying reasons for a relation between governance and conservatism, and aid empirical work. This paper provides an explanation based on the efficiency of board monitoring.

We construct a stylized economic model of a firm in which the board of directors hires and monitors the managers. There are two types of managers: those who fit the production process and are more productive and those who do not fit. Managerial type is unknown on the contracting date. The outcome of the production process is unobservable and the board relies on the accounting system that provides imperfect information about the outcome. Using the accounting signal, the board updates its expectation about the manager's type and decides whether to engage in costly monitoring. We capture the board's monitoring efficiency by its effectiveness (i.e., the probability that monitoring reveals the incumbent manager's type) and its cost of monitoring. Based on the accounting information and the information generated from monitoring, the board decides whether to retain the manager for another period or to hire a new manager. Thus, the accounting system serves a dual purpose: First, it provides direct information about the manager's type and, second, it directs the board's decision whether to engage in costly monitoring.

\footnotetext{
1 See, e.g., Watts (2003) for possible reasons for conservatism, Penalva and Wagenhofer (2019) with a survey of theoretical notions and empirical proxies of conservatism in a debt contracting setting, and Barker (2015) for the evolution of conservatism in accounting standards.

2 Bushman and Smith (2001), Armstrong et al. (2010) and Brown et al. (2011) survey the literature.
} 
Our analysis shows that a board with higher monitoring efficiency prefers more conservative accounting. Conservatism increases the likelihood of obtaining unfavorable signals and, at the same time, it decreases the precision of unfavorable relative to favorable signals. Absent monitoring, conservatism is undesirable because the higher probability and lower precision of unfavorable signals induces the board to replace the manager too often. Conservatism becomes desirable if the accounting information directs the board's monitoring decision. If the board is an efficient monitor, then it will monitor particularly after an unfavorable report and amend the imprecise accounting information by its information from monitoring. A favorable report is precise enough that the board does not monitor, so it saves monitoring cost. We provide explicit conditions under which conservative accounting is optimal, that is, more efficient boards demand more conservatism. Furthermore, we offer several comparative statics with specific predictions that can guide empirical tests of the relation between governance and conservative accounting.

The theoretical foundations of this paper are information economics and formal agency theory. ${ }^{3}$ These theories employ models of firms in which managers take productive actions and the role of the board is to contract with the managers and monitor their behavior. Accounting information can be useful for either responsibility, and designing the accounting system affects firm value through its impact on decisions taken by the players.

Specifically, this paper is related to the theoretical literature on corporate governance that focuses on management retention decisions and/or board monitoring. ${ }^{4}$ Crémer (1995) considers a moral hazard setting with a manager of unknown type. After observing an unfavorable signal, the board retains the manager if it finds the manager is a good fit. This additional chance of retention reduces the manager's work incentives. Similar to our paper, Hermalin and Weisbach (1998) consider a board that collects information about the manager and uses this information to make the replacement decision. They focus on how board structure, particularly its independence, affect this decision. ${ }^{5}$ Hermalin (2005) studies costly monitoring by a board that decides whether to replace an incumbent with an external manager and finds that a more independent board increases monitoring and is more inclined to hire an external candidate. Chaigneau and Sahuguet (2019) examine the relation between the quality of a performance measure and the value of board monitoring. They find that these two sources of information about a manager's type can be complements or substitutes. Laux (2008) examines a board's decision to replace an incumbent manager. The accounting system is informative for this decision and, because the board cannot precommit to a replacement strategy, it removes the manager too often. Drymiotes and Sivaramakrishnan (2012) analyze a board that contracts with the manager and provides monitoring and advisory tasks in a setting

\footnotetext{
3 See, e.g., Jensen and Meckling (1976), Milgrom and Roberts (1992) and Christensen and Demski (2003).

${ }^{4}$ See Laux (2013) for a survey of this literature.

5 Consistent with their prediction, Guo and Masulis (2015) find evidence for a causal link between board independence and a resulting higher turnover-performance sensitivity.
} 
with agency problems between shareholders and the board and between the board and the manager. Tian (2014) studies the effect of board monitoring on the manager's incentive to acquire information about a project. Effective board monitoring reduces the manager's compensation risk and the incentive to search for information. These papers do not examine the value of biased information through conservative accounting.

Other papers consider conservative accounting in specific board decision situations. Li (2001) shows that a conservative decision rule can serve as a remedy to free-riding in a group to acquire costly private information in the process. The information acquisition aspect bears some resemblance to our paper. Caskey and Laux (2017) consider board approval of an investment project based on a report by the manager who obtains private benefits from investment and has an incentive to manipulate the report upwards. They find that more conservatism improves the investment decision but also induces more manipulation and the tradeoff depends on the manager's cost of manipulation. Our paper considers a management retention decision, and we emphasize the importance of the board actively acquiring information in addition to the manager's accounting report. Balakrishnanet al. (2019) study an agency model in which the principal uses the accounting system to motivate the agent to exert effort and to decide about retention of the manager. Conservatism is useful to motivate effort but increases the risk of replacing a capable manager too often. Our paper does not consider productive effort but focuses on board monitoring. Smith (2007) considers a regulator who sets the level of conservatism and a firm that makes investment and abandonment decisions based on the accounting signal, before selling the firm to new investors. He finds either conservatism or aggressiveness to be optimal, but does not consider board monitoring.

The rest of this paper is organized as follows. In the next section, we describe the model with the firm, the board, and the manager, and we specify the accounting system and conservatism. Section 3 contains the main analysis and results for different uses of accounting information. Section 4 states empirical predictions derived from the results. Finally, Sect. 5 concludes.

\section{Model}

We consider a two-period economy. A firm owns a production technology that requires specific managerial input. The managers are one of two types, type $A$ with probability $q \in(0,1)$ or type $B$ with probability $(1-q)$, where the type comprises the fit of the manager's skills with the firm's technology or strategy, which is firm specific. A type $A$ manager is a better fit and produces a stochastically higher outcome than a type $B$ manager. The manager's type is unknown to both the manager and the firm at the time the manager is hired. The compensation paid to the manager is equal to the market wage, which is normalized to zero. All parties are risk neutral. To identify benefits of conservatism in a most simple way, we assume there is no moral hazard with regard to managerial effort.

The shareholders install a board of directors that is responsible for searching for and contracting with the manager. The board hires a manager at the beginning of 
the first period and writes a two-period contract. After the first period, it decides to retain or replace the manager, in which case it hires a new manager from the same pool. Replacing the incumbent manager and hiring a new manager (for one period) entails a replacement cost $k \geq 0$. This cost includes costs of the premature contract termination and transaction costs associated with hiring a replacement manager.

The composition of the board determines how effective it is in its monitoring capacity. We capture the board's monitoring efficiency by two parameters. One is the probability $\lambda \in[0,1]$ that it learns the manager's actual type through its monitoring activities. The other is the direct monitoring cost $c>0$, which captures the costs of board effort, the costs of collecting or requesting information, and indirect costs from the disruption of normal business by monitoring activities. ${ }^{6}$ Board monitoring is more efficient if it is more effective (higher $\lambda$ ) and/or if it is less costly (lower $c$ ).

The outcome of the production process in each period is either success, yielding an incremental outcome $x>0$, or failure, yielding a base outcome that we normalize to zero. A type $B$ manager is successful with a base probability $p_{0} \in(0,1-p)$ and a type $A$ manager is always more successful with a probability of $p_{0}+p$, where $p>0$. Henceforth, we set $p_{0}=0$ to reduce complexity; assuming $p_{0}>0$ does not alter the results except that the exact conditions for which they apply also depend on $p_{0}$.

The expected (incremental) value of employing a type $A$ manager is $G=p x$. We assume that it pays to replace a known type $B$ manager at the beginning of the second period, that is,

$$
q G-k>0
$$

The actual outcome is not observable and not contractible, for example, because it includes non-monetary or long-term benefits for the firm. Therefore, the board cannot use the outcome in period 1 for its decision to retain or replace the manager. The basic information problem is due to the manager's and the board's uncertainty about the manager's type, which is why accounting information can be useful. The assumption that not even the manager knows the type ex ante avoids the adverse selection issue. ${ }^{7}$

The financial accounting system produces a signal (e.g., earnings) $y \in\left\{y_{L}, y_{H}\right\}$ that provides imperfect information about the outcome. The accounting system is fully characterized by the two conditional probabilities $\left(f_{L}, f_{H}\right)$, where $f_{j} \in[0,1]$ is the probability that the accounting system reports $y_{L}$ if the outcome is 0 and $y_{H}$ if the outcome is $x$. The probabilities $1-f_{L}$ and $1-f_{H}$ are the overstatement and understatement errors, respectively. Assume without loss of generality that $f_{L}>1-f_{H}$ to ensure that $y_{L}$ is more likely to be reported than $y_{H}$ if the outcome equals 0 . The

\footnotetext{
${ }^{6}$ Board monitoring is different from auditing: Auditing provides verification of the outcome as reported in the financial statements (what the audit committee is concerned with), whereas our board monitoring is concerned with the type of the manager, which affects productivity.

7 This assumption is similar to that of others, for example, Hermalin and Weisbach (1998) and Arya et al. (1998). It also eliminates concerns about the market pricing of managerial talent and the resulting compensation and reservation utility constraint, which would create a broad set of manager types on the market, based on their prior achievements. Beyer et al. (2014) study accounting information in an adverse selection and moral hazard setting.
} 

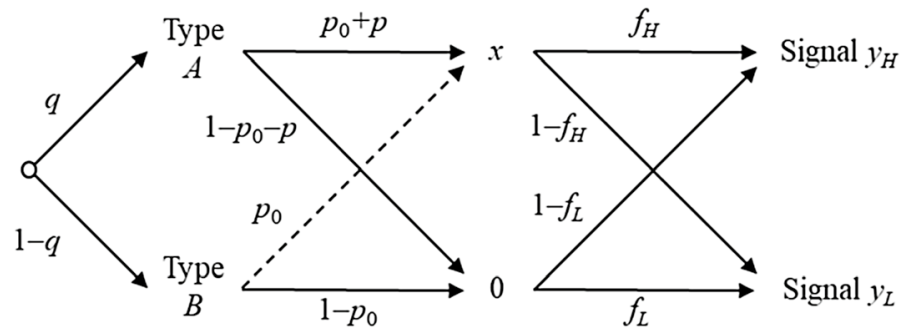

Fig. 1 Production process and accounting system. The probability of a type $A$ (good fit) manager is $q$ and that of a type $B$ manager (bad fit) is $(1-q)$. The outcome of the production process in each period is either success, yielding an incremental outcome $x>0$, or failure, yielding a base outcome that we normalize to zero. A type $B$ manager is successful with a base probability $p_{0}$ (which we set to 0 in the main analysis) and is unsuccessful with probability $\left(1-p_{0}\right)$; a type $A$ manager is more successful with an incremental probability of $p$. The probability that an unsuccessful outcome generates a low signal $y_{L}$ is $f_{L}$, and the probability that a successful outcome generates a high signal $y_{H}$ is $f_{H}$. The accuracy of the accounting system $F \equiv f_{L}+f_{H}-1$ is constant. An accounting system with $f_{L}>f_{H}\left(f_{L}<f_{H}\right)$ is conservative (aggressive)

assumption $f_{L}>1-f_{H}$ also implies $f_{H}>1-f_{L}$. Figure 1 depicts the production technology and the accounting system.

Since we are interested in the bias of the accounting system, we assume that an increase in the overstatement error leads to an equal decrease in the understatement error, which implies $F \equiv f_{L}+f_{H}-1 .^{8}$ The accounting system is then fully characterized by $\left(f_{L}, F\right)$, where $F \in[0,1]$ and $f_{j} \in[F, 1]$. The parameter $F$ captures the accuracy of the accounting system: A perfect accounting system is described by $F=1$ and a totally uninformative accounting system by $F=0$. To avoid extreme cases, we exclude both boundary values and take $F \in(0,1)$ as given, and we are interested in the optimal combination of feasible $\left(f_{L}, f_{H}\right){ }^{9}$

We define a neutral accounting system by $f_{L}=f_{H}$, which implies that the conditional error probabilities are independent of the respective signals. A conservative accounting system is characterized by $f_{L}>f_{H}$, that is, a low outcome is more likely to generate signal $y_{L}$ than a high outcome is to generate signal $y_{H}$. An aggressive accounting system is characterized by $f_{L}<f_{H}$. This stylized characterization of the accounting system describes conditional conservatism, since the signal produced is informative, and it is consistent with that of other characterizations, such as those in Gigler and Hemmer (2001) and Gigler et al. (2009). The asymmetry of the accounting system introduced by choosing $f_{L}$ (and implicitly, $f_{H}$ ) is the parameter of interest in our model, and we assume that there is no cost of varying the degree of conservatism.

\footnotetext{
8 Note that the accuracy is equal to 1 minus the sum of the over- and understatement error.

9 This assumption helps to gain more insights into the effects of the bias. Our results do not fundamentally depend on how exactly an increase in $f_{L}$ translates into a decrease in $f_{H}$. For more general assumptions on biases see, e.g., Caskey and Laux (2017) and Balakrishnan et al. (2019).
} 


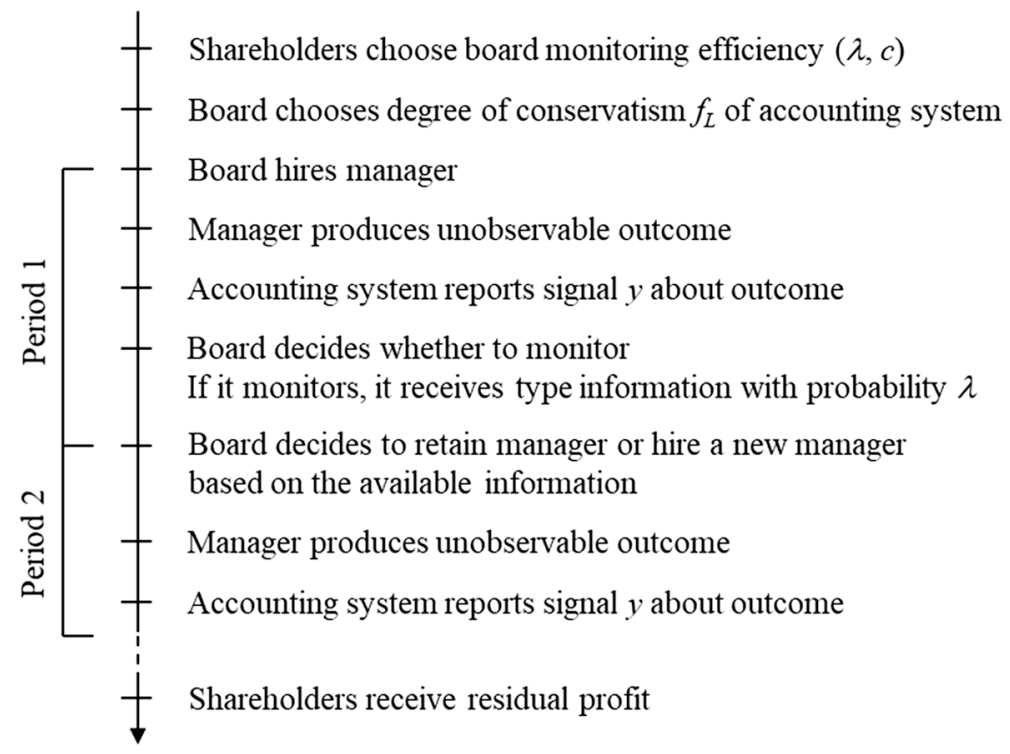

Fig. 2 Timeline of the model

Figure 2 summarizes the timeline of the model. At the beginning, the shareholders choose the board members, whose composition determines the board's efficiency parameters $\lambda$ and $c$. We assume that the board acts in the interest of shareholders. The board then decides on the accounting bias, in particular, the level of conservatism $f_{L}$, given a predetermined accuracy $F$ of the accounting system. Actions that determine the level of conservatism include the choice or specific implementation of an accounting system, observable adjustments to accounting numbers (e.g., alternative performance measures), independent directors, monitoring by active investors, or easy access to courts that predominantly pursue overstatements of earnings.

Next, the board hires a manager out of the pool of available managers and, after receiving the accounting information, it decides on monitoring and then on replacing the manager in order to maximize firm value. ${ }^{10}$ If retained, the incumbent manager continues to produce; otherwise a new manager from the pool is hired. We do not model subsequent periods because they do not add much to our understanding the role and characteristics of the accounting system.

\footnotetext{
${ }^{10}$ We do not consider frictions, e.g., being friends with the incumbent manager, which could bias the board's decisions and change some of our results.
} 


\section{Basic results}

We develop our results by separately considering three cases that can arise. In the first case, the accounting signal is only useful for the replacement decision. In the second case, the accounting signal is only useful for the board's monitoring decision, but it is not sufficiently informative to influence the replacement decision. Finally, in the third case, the accounting signal informs both the monitoring and replacement decision. Together, these cases describe all possible results. Formal proofs are in Appendix.

\subsection{Accounting system informs replacement}

We begin with the case in which monitoring is inefficient because it is either too costly (high $c$ ) or ineffective (low $\lambda$ ). Then the accounting system is the only source for the board's replacement decision. Conditional on the respective signals, the board revises the probability $q$ of the incumbent manager being type $A$ to

$$
\begin{gathered}
q_{L} \equiv \operatorname{Pr}\left(A \mid y_{L}\right)=\frac{q p\left(1-f_{H}\right)+q(1-p) f_{L}}{\operatorname{Pr}\left(y_{L}\right)}=\frac{q f_{L}-q p F}{f_{L}-q p F}<q, \\
q_{H} \equiv \operatorname{Pr}\left(A \mid y_{H}\right)=\frac{q p f_{H}+q(1-p)\left(1-f_{L}\right)}{\operatorname{Pr}\left(y_{H}\right)}=\frac{q p F+q\left(1-f_{L}\right)}{q p F+1-f_{L}}>q .
\end{gathered}
$$

If the signal $y_{H}$ realizes, the conditional probability that the incumbent manager is type $A$ is $q_{H}>q$, and it is always better to retain the manager in the second period because the expected outcome is $q_{H} G>q G \geq q G-k>0$.

Upon observing $y_{L}$, the probability of a type $A$ manager without additional information is $q_{L}<q$, and the board trades off the expected gain of productivity and the replacement cost $k$ that the firm incurs if a new manager is hired. The board removes the manager and hires a new manager if $q_{L} G<q G-k$, and it retains the incumbent manager otherwise.

Using the optimal retention decisions, the firm's expected profit in period 2 before the signal realizes is

$$
\begin{aligned}
\Pi_{N} & =\operatorname{Pr}\left(y_{H}\right) q_{H} G+\operatorname{Pr}\left(y_{L}\right) \max \left\{q_{L} G ; q G-k\right\} \\
& =q G+\operatorname{Pr}\left(y_{L}\right) \max \left\{0 ;\left(q-q_{L}\right) G-k\right\} .
\end{aligned}
$$

The expected profit consists of the ex ante expected profit $q G$ and the option value of replacing the manager upon observing $y_{L}$.

Proposition 1 If the board never monitors, then aggressive accounting $\left(f_{L}=F\right)$ is optimal and strictly optimal if 


$$
\frac{p q(1-q)}{1-p q}>\frac{k}{G}
$$

To see why aggressive accounting dominates, note that without any information about the manager's type, the board would always retain the manager and save the replacement cost $k$. A signal is useful only if it leads the board to deviate from that decision and replace the manager. A low signal, $y_{L}$, is more indicative of a type $B$ manager and therefore replacement can only be optimal if $y_{L}$ is observed. An aggressive accounting system minimizes the probability $\operatorname{Pr}\left(y_{L}\right)$ and, at the same time, maximizes the precision of the signal $y_{L}$, that is, it ensures that the conditional probability of a type $A$ manager is the lowest under $y_{L}$ so that erroneous replacement decisions are minimized for a given accuracy. Ex ante, due to the law of iterated expectations, a decrease in the probability that $y_{L}$ realizes (and the corresponding increase in signal precision) has no effect on the expected profit before taking into the account the replacement cost, but it strictly reduces the expected replacement cost, $\operatorname{Pr}\left(y_{L}\right) k$, and is therefore beneficial.

The reason why aggressive accounting is preferable in our analysis is similar to that in Gigler et al. (2009), who study a debt contracting setting in which a covenant based on accounting information determines the ownership rights of a project. They show that aggressive accounting is optimal because the project must be a priori profitable so the accounting signal is designed to specifically identify bad projects with great precision. ${ }^{11}$ In our model, replacing a manager generates an expected profit of $q G-k>0$, so the board wants to have the most precise information about a type $B$ manager, which requires an aggressive accounting system.

Equation (3) reflects the condition that the board replaces the manager if $y_{L}$ realizes, that is $\left(q-q_{L}\right) G>k$, with $q_{L}$ determined under $f_{L}=F$. If (3) holds then using the aggressive accounting system (with $f_{L}=F$ ) is strictly valuable for making the replacement decision. Otherwise, the board retains the manager regardless of the signal and the accounting system has no decision value. In that case, the choice of $f_{L}$ is arbitrary, so $f_{L}=F$ is weakly preferable.

\subsection{Accounting system informs monitoring}

We now consider the usefulness of the accounting system only for the board's monitoring decision but not for the replacement decision directly. If the board finds out the manager's type through monitoring, it will replace a type $B$ manager and retain a type $A$ manager because the monitoring is perfect and substitutes for the information content in the accounting signal. Absent monitoring, the board optimally retains the manager, regardless of which signal is reported. As discussed in Proposition 1, the accounting system is irrelevant for the replacement decision if $\frac{q p(1-q)}{1-q p} \leq \frac{k}{G}$.

\footnotetext{
${ }^{11}$ Follow-up papers, such as Caskey and Hughes (2012), Fan and Zhang (2012), and Li (2013), study variations of the setting of Gigler et al. (2009) and find that conservatism can be beneficial in their settings.
} 
The board decides whether to monitor after observing the realized accounting signal $y_{i}, i=L, H$. Given $y_{i}$, it updates the probability of a type $A$ manager from $q$ to $q_{i}$. The board decides to monitor if the expected benefit from monitoring exceeds its cost:

$$
\lambda\left(1-q_{i}\right)(q G-k)>c .
$$

The benefit results from replacing the manager in case monitoring reveals a type $B$ manager that would produce a profit of zero in the second period (probability $\lambda$ ). The expected profit from hiring a new manager is $q G-k>0$. If monitoring is effective, the board identifies a type $B$ manager with probability $\left(1-q_{i}\right)$, where $q_{i}$ depends on the accounting signal, which again depends on the degree of conservatism. Note that because $q_{H}>q_{L}$, the expected benefit (left-hand side of condition (4)) is greater for $y_{L}$ than for $y_{H}$, which means that the board never monitors only at $y_{H}$, but does so either only at $y_{L}$ or regardless of the signal.

The relative profitability of the monitoring strategies depends on the characteristics of the accounting system, because they affect the probability of observing $y_{L}$ and the updating of the probability of the two types contingent on the signal.

Proposition 2 If the accounting system is irrelevant for the replacement decision, then the optimal solution consists of:

i. Monitoring only at $y_{L}$ if

$$
c<\frac{1-q}{1-q p} \lambda(q G-k)
$$

and no monitoring otherwise; and

ii. Conservative accounting $\left(f_{L}=1\right)$ if

$$
c<\lambda(1-q)(q G-k)
$$

and aggressive accounting $\left(f_{L}=F\right)$ otherwise.

We first show the ex post monitoring strategy given the board observes the signal $y_{L}$ or $y_{H}$. If the monitoring cost $c$ is high, no monitoring is optimal; if it is intermediate, monitoring only at $y_{L}$ is optimal, and for a sufficiently low cost, always monitoring (regardless of the signal) is optimal. Next, we determine the expected profits for each monitoring strategies. The expected profit for always monitoring or never monitoring is independent of the accounting system, whereas it depends on $f_{L}$ for monitoring only at $y_{L}$. The proposition states that monitoring only at $y_{L}$ is optimal if $c$ is below a threshold. Monitoring only at $y_{H}$ is never optimal because the chance of identifying a type $B$ manager is strictly higher for $y_{L}$ than for $y_{H}$ as there are relatively more $B$ managers in the $y_{L}$ pool. 
The main result in Proposition 2 is that the optimal accounting system is conservative for any $c<\lambda(1-q)(q G-k)$. This threshold is strictly lower than that for monitoring only at $y_{L}$ (Eq. 5), which implies that monitoring at $y_{L}$ always occurs if conservative accounting is preferred. While there is another threshold for $c$, that always monitoring becomes preferable for lower $c$, this threshold approaches 0 under conservative accounting. ${ }^{12}$ Intuitively, maximum conservatism, $f_{L}=1$, maximizes the contingent probability of a type $A$ manager, $\left.q_{H}\right|_{f_{L}=1}=1$, but monitoring entails a positive expected monitoring cost. Therefore, monitoring only at $y_{L}$ with $f_{L}=1$ is as effective as always monitoring because it results in the same likelihood of revealing a type $B$ manager but saves expected monitoring costs. Comparing the expected profits, their difference is

$$
\begin{aligned}
\Pi_{L}^{0}\left(c, f_{L}=1\right)-\Pi_{L H}^{0}(c) & =[\lambda(1-q)(q G-k)-c+q p F c]-[\lambda(1-q)(q G-k)-c] \\
& =q p F c \geq 0 .
\end{aligned}
$$

Proposition 2 also states that monitoring only at $y_{L}$ remains beneficial for $\lambda(1-q)(q G-k)<c<\frac{1-q}{1-q p} \lambda(q G-k)$. However, the optimal accounting system switches to an aggressive system for this set of costs $c$. Reducing $f_{L}$ from 1 to $F$ has two effects: It lowers the probability of monitoring $\operatorname{Pr}\left(y_{L}\right)$, which saves monitoring costs, but it also lowers the probability of identifying (and replacing) a type $B$ manager. The positive effect from the reduction of the expected monitoring cost dominates until the cost becomes so high, $c>\frac{1-q}{1-q p} \lambda(q G-k)$, that no monitoring becomes optimal.

\subsection{Accounting system informs both monitoring and replacement}

In the general case, the accounting system fulfills a dual role: it is informative for the monitoring decision as well as the replacement decision, if there is no monitoring or if monitoring is ineffective. Board monitoring can be valuable after either signal is observed: For signal $y_{H}$, the board would retain the manager without additional information, but monitoring is helpful in identifying and replacing a type $B$ manager. For signal $y_{L}$, the board would replace the manager without additional information, but monitoring can identify a type $A$ manager, which is then retained. A type $A$ manager generates an additional profit of $G-(q G-k)=(1-q) G+k$.

Formally, this setting combines the two cases underlying Propositions 1 and 2. Proposition 1 shows that an aggressive accounting system is more beneficial for the replacement decision based on the accounting information, whereas Proposition 2 states that for an efficient board, conservative accounting is more beneficial for the monitoring decision. The following proposition describes the result of the tradeoff between these two effects.

\footnotetext{
12 This result holds under our maintained assumption that the base productivity $p_{0}=0$. Otherwise, there is a lower interval in which always monitoring is preferred. Yet, as long as the accounting system is informative, conservative accounting prevails for low $c$.
} 


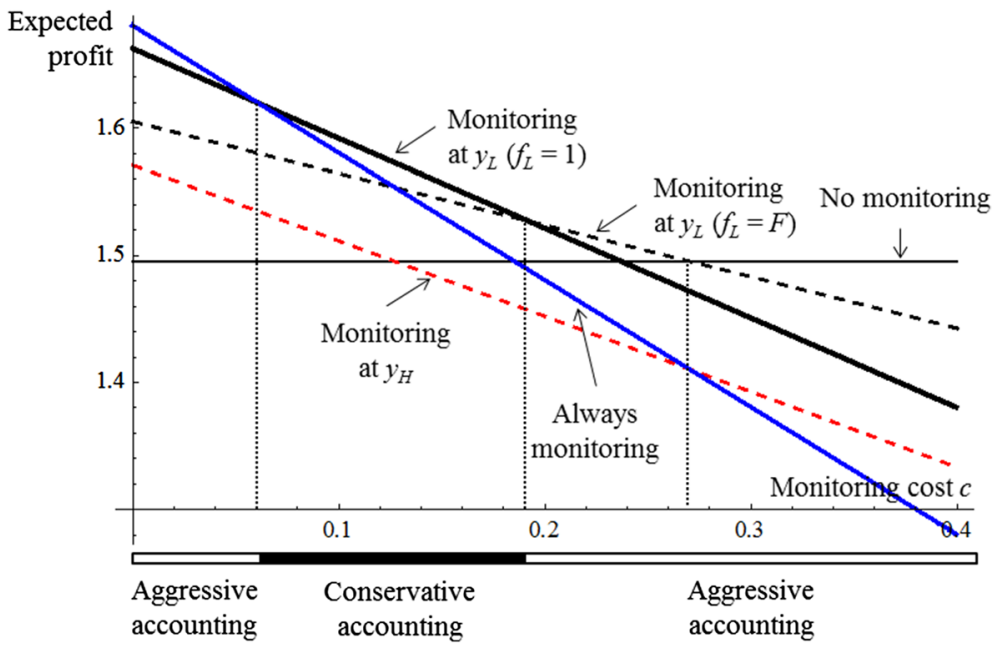

Fig. 3 Conservative accounting and monitoring strategy. This graph illustrates the optimal monitoring strategy and the area of the monitoring costs in which conservative accounting is desirable, as stated in Proposition 3. The parameters are: $F=0.7, q=0.7, p=0.6, G=2, k=0.2$, and $\lambda=0.7$

Proposition 3 Assume the accounting system is relevant for the replacement decision. Conservative accounting $\left(f_{L}=1\right)$ is optimal if and only if $c \in[\underline{c}, \bar{c})$ and $\bar{c}>\underline{c}$, where

$$
\underline{c} \equiv \frac{(1-F)(1-\lambda) k}{q p F}
$$

and $\bar{c}$ is complicated and stated in the proof. If conservative accounting is optimal, monitoring only at $y_{L}$ is the optimal monitoring strategy. If these conditions are not satisfied, aggressive accounting $\left(f_{L}=F\right)$ is optimal.

Figure 3 illustrates the results. It depicts all possible monitoring strategies together with their respective optimal accounting bias. Given the specific parameter values, conservative accounting is optimal for $c \in[0.06,0.19)$.

The proposition first shows that the main result from Proposition 2: monitoring only at $y_{L}$ is necessary for conservative accounting $\left(f_{L}=1\right)$ to be optimal, carries over to this setting. In Proposition 2, conservative accounting dominates for all $c$ below an upper bound. According to Proposition 3, always monitoring is preferable for very low costs. The reason is that aggressive accounting is advantageous in the case of no monitoring (see Proposition 1), which is the second term of the expected profit for no monitoring,

$$
\Pi_{N}^{R}=q G+\operatorname{Pr}\left(y_{L}\right)\left(q G-k-q_{L} G\right) .
$$

This advantage decreases in $f_{L}$. Therefore, switching to $f_{L}=1$ generates a loss of $(1-F) k$ and, in order to make monitoring only at $y_{L}$ optimal, it must compensate for this loss. 
Proposition 3 also states an upper bound $\bar{c}$ for conservatism to prevail. As we show in the proof, this bound is the minimum of three thresholds:

$$
\begin{gathered}
\bar{c}_{L} \equiv \lambda q[(1-q) G+k]-k, \\
\bar{c}_{H} \equiv \frac{1}{1-2 q p}\left[(1-p) \lambda q[(1-q) G+k]-\frac{1-F}{F}(1-\lambda) k\right], \\
\bar{c}_{N} \equiv \frac{1}{1-q p F}[(1-p F) \lambda q[(1-q) G+k]-(1-F) k] .
\end{gathered}
$$

The conditions assure that the optimal strategy, i.e., monitoring at $y_{L}$ and $f_{L}=1$, is preferable to the other monitoring strategies (all of which have $f_{L}=F$ ). The first bound $\bar{c}_{L}$ determines the switch from conservative to aggressive accounting under monitoring only at $y_{L}$. The reason for the switch is that monitoring becomes so costly that it is optimal to decrease the probability of monitoring activities.

The two other upper bounds make sure that monitoring at $y_{H}$ does not dominate monitoring at $y_{L}$ together with conservative accounting. The upper bound $\bar{c}_{H}$ results from comparing monitoring at $y_{L}$ with monitoring at $y_{H}$. Recall that monitoring at $y_{H}$ is most effective for $f_{L}=F$. Different from the case underlying Proposition 2, monitoring at $y_{H}$ can now be preferable to monitoring at $y_{L}$. Replacing a type $B$ manager after monitoring at $y_{H}$ yields an incremental benefit of $\lambda\left(1-q_{H}\right)(q G-k)$, whereas retaining a type $A$ manager after monitoring at $y_{L}$ yields $\lambda q_{L}[(1-q) G+k]$. If the former is larger than the latter, it can be optimal to increase the priori probability of signal $y_{H}$, which is equivalent to increasing the aggressive bias of the accounting system. Finally, the upper bound $\bar{c}_{N}$ results from comparing monitoring at $y_{L}$ with never monitoring. As stated above, monitoring at $y_{L}$ with $f_{L}=1$ induces a disadvantage compared to the other monitoring strategies and to never monitoring, which must be overcome by the benefit from a better monitoring efficiency to make conservatism optimal.

It is possible that the set $c$ for conservative accounting is empty for a particular $\lambda$, that is, $\underline{c} \geq \min \left\{\bar{c}_{L}, \bar{c}_{H}, \bar{c}_{N}\right\}$. Corollary 1 identifies two special cases in which the lower threshold for conservatism $\underline{c}=0$ and the upper threshold $\bar{c}>0$, which closely resembles the result in Proposition 2.

Corollary 1 If $\lambda=1$ or $k=0$, there always exists a non-empty set $c \in[0, \bar{c})$ for which conservative accounting $\left(f_{L}=1\right)$ is optimal.

Taken together, Proposition 3 establishes that conservative accounting is desirable if the board is efficient in monitoring and the accounting information is relevant for the monitoring decision.

Figure 4 illustrates the results for a variation of the monitoring cost $c$ and effectiveness $\lambda$. The parameters are the same as in Fig. 3, except that we vary $k$ to illustrate Propositions 2 and 3. In Fig. 4a $k=0.5$, so condition (3) is not satisfied. Conservative accounting with monitoring only at $y_{L}$ is optimal in the gray shaded area, which includes low monitoring costs and high effectiveness. Holding $\lambda$ constant, 
(a) Accounting irrelevant to the replacement decision

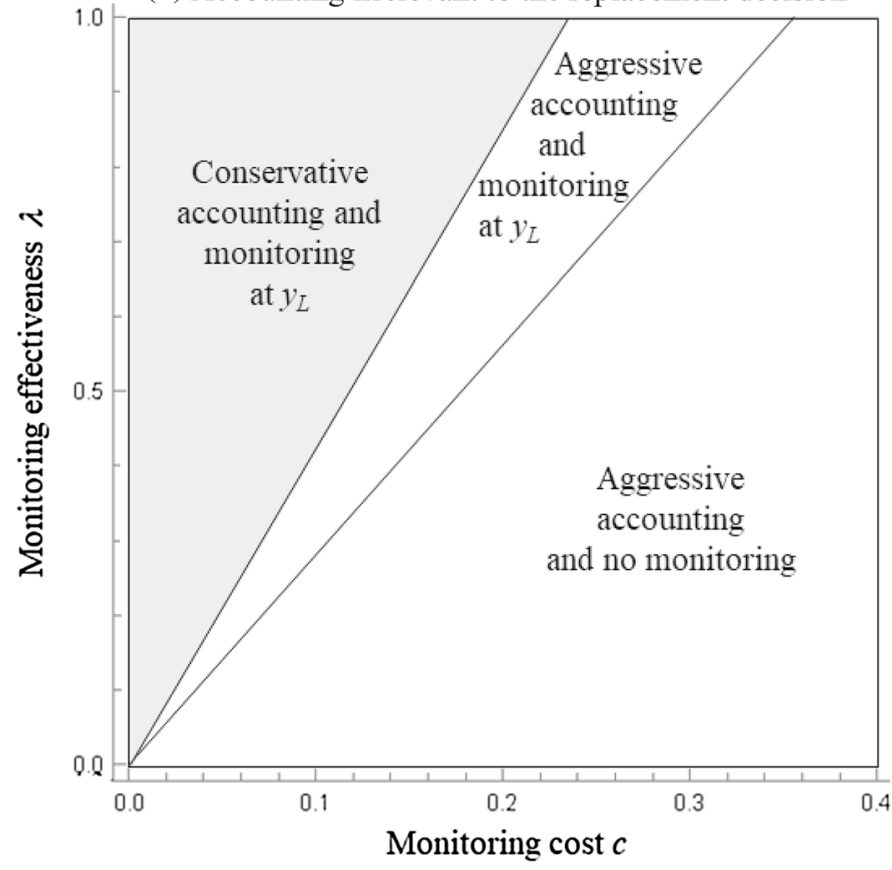

(b) Accounting relevant to the replacement decision

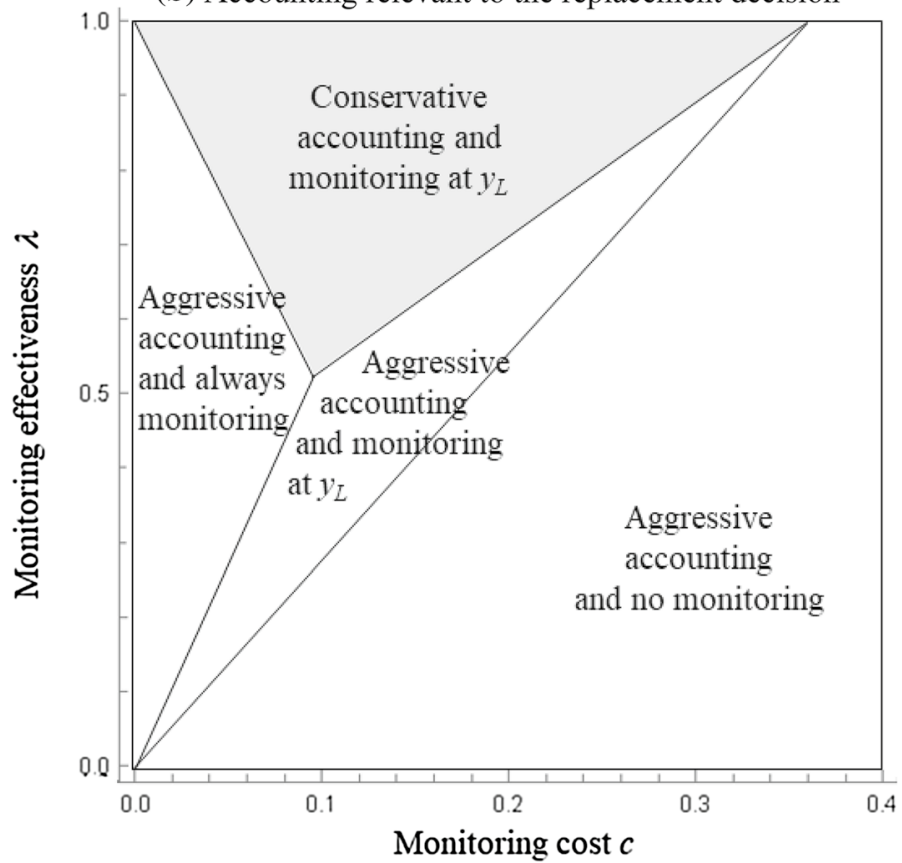

Fig. 4 Conservative accounting and monitoring strategy. a Accounting irrelevant to the replacement decision. b Accounting relevant to the replacement decision. a illustrates the result in Proposition 2, and $\mathbf{b}$ illustrates that in Proposition 3. The parameters are: $F=0.7, q=0.7, p=0.6, G=2, k=0.5$ (a) and $k=0.2$ (b) 
an increase of $c$ eventually renders aggressive accounting preferable, first retaining monitoring at $y_{L}$, and later switching to no monitoring. Figure $4 \mathrm{~b}$ uses $k=0.2$ as in Fig. 3. In this case always monitoring becomes optimal for very low monitoring costs and particularly for an intermediate monitoring effectiveness $\lambda$. Monitoring only at $y_{H}$ is always dominated in this example.

\section{Empirical predictions}

This section provides several comparative static results that can guide empirical tests of the interaction between board monitoring efficiency and characteristics of the accounting system. Empirical research suggests such a link. For example, Beekes et al. (2004), Ahmed and Duellman (2007), and García Lara et al. (2009) provide evidence that firms with boards whose characteristics are indicative of high monitoring ability report more conservatively. Since it can be difficult to distinguish different possible reasons for this observation, our results concerning monitoring efficiency can help to identify some of the sources for the demand for conservatism by providing specific predictions.

The first prediction suggests that a board that is more efficient in monitoring prefers more conservative accounting. Higher board monitoring efficiency arises from higher effectiveness $\lambda$ and/or a lower cost $c$ of monitoring.

\section{Corollary 2 The likelihood that conservative accounting is optimal}

i. Increases in monitoring effectiveness $\lambda$; and

ii. Decreases in the monitoring cost $c$, except for very low $c$ when always monitoring is optimal.

These predictions follow directly from inspection of the conditions in Proposition 2 and 3: If accounting is relevant only for monitoring, then Proposition 2 shows that conservative accounting prevails if $c<\lambda(1-q)(q G-k)$, which is more likely satisfied if $c$ is small and/or $\lambda$ is large. If accounting is also relevant when monitoring does not identify the manager's type (probability $1-\lambda$ ), then Proposition 3 reveals that the upper threshold for the monitoring cost $c$ increases with $\lambda{ }^{13}$ Furthermore, the lower threshold $\underline{c}$ decreases in $\lambda$. We show in Proposition 3 , that, for very low monitoring costs, the board always monitors, regardless of the accounting information.

The optimality of conservative accounting under higher $\lambda$ stems from the fact that it ensures there is little loss from reducing monitoring from always monitoring to monitoring only at $y_{L}$ : by pushing type $B$ managers into the $y_{L}$ pool, more effective monitoring can better identify these type $B$ managers. At the same time, not monitoring at $y_{H}$ saves monitoring costs. As long as these cost savings exceed the loss

\footnotetext{
13 Note that $\bar{c}_{H}$ can decrease in $\lambda$, but this occurs only if it is negative. There is no room for conservative accounting in that case.
} 
from reducing monitoring, conservative accounting is preferred. Thus, conservative accounting complements efficient board monitoring, establishing a positive association between strong corporate governance (measured by high monitoring efficiency) and conservative accounting.

In our main analysis, we assume that the accuracy of the accounting system $F \in(0,1)$ is fixed. However, accounting standards, their implementation in the firm, internal control systems, and corporate governance can affect the accuracy. The next prediction considers the effect of a change in the accuracy $F$ of the accounting system.

Corollary 3 The likelihood that conservative accounting is optimal increases in the accuracy $F$, except if $\bar{c}=\bar{c}_{N}$.

The value of the accounting system increases in $F$, regardless of which monitoring strategy is implemented. The corollary states that, generally, greater accuracy implies more conservatism. The one exception arises from the behavior of $\bar{c}_{N}$. As a determinant of the upper bound for $c$ in Proposition 3, the effect of varying $F$ on $\bar{c}_{N}$ depends on several parameters. Intuitively, increasing accuracy renders board monitoring less important because the accounting system provides better information already. Moreover, for higher $F$ the difference between conservative and aggressive accounting diminishes as both $f_{L}$ and $f_{H}$ approach one.

Our final prediction states the association of the firm's potential profit and the likelihood of conservative accounting.

Corollary 4 The likelihood that conservative accounting is optimal increases in the productive outcome $x$.

This corollary directly follows from the conditions in Propositions 2 and 3. Intuitively, a higher productive outcome $x$ increases the additional expected outcome of a type A manager, which is $G=p x$, but leaves the replacement cost $k$ and the monitoring cost $c$ unaffected, so that the conditions for conservative accounting are more likely satisfied. The result suggests that firms with more profit potential and growth opportunities are more likely to report conservatively.

\section{Conclusions}

This paper establishes a positive relation between the monitoring efficiency of boards and conservative accounting in a model that focuses on one of the most important decisions of boards, which is to retain or replace an incumbent manager. The accounting system provides information that is both directly useful for this purpose and indirectly useful by directing the board's monitoring decision to seek additional information. Conservative accounting is desirable if the optimal monitoring strategy consists of monitoring only after an unfavorable accounting signal and the 
board is efficient in monitoring. While conservative accounting increases the probability of an unfavorable signal and tends to trigger replacement too often, the additional monitoring is effective in making the replacement decision more precise.

This result complements prior explanations for a positive relation between conservatism and corporate governance strength and helps empirical research to better identify the reasons for findings consistent with this relationship. In our model, causality goes from board efficiency to the desirability of conservative accounting: that is, more efficient boards demand more conservatism. It is possible to consider a reverse chain of causality, in which the degree of conservatism is given and shareholders decide about the board composition, including its monitoring efficiency. That would require explicit costs and benefits of different board compositions, as otherwise it is obvious that without costs maximum efficiency would be most desirable. Further research might consider the effects of board composition, for example, the proportion of board members that are good monitors and those that are good advisors to management. Increasing monitoring efficiency in this way is then likely to reduce advising capacity.

There are several possible extensions to our model. An extension is the explicit consideration of conflicts of interest between the manager and the board or the shareholders. Board governance is an instrument to mitigate moral hazard of managers. In this case, the accounting system can have an additional purpose besides those we consider. ${ }^{14}$ Of course, using the accounting system for additional purposes would add new tensions, which can affect the optimal design of the accounting system.

Another extension is to introduce earnings management opportunities by management. For example, a more effective board may be better able to detect and discourage earnings management. ${ }^{15}$ Prior literature has shown that biased accounting can also help to mitigate agency problems. Incorporating an earnings management opportunity would add another tradeoff to those present in our setting.

Extending the model to multiple periods can also yield further interesting insights. In a multiperiod setting, the unwinding of prior conservative reports obfuscates the information content of the newly generated information if it is not separately disclosed. A multi-period setting can allow for learning more about the manager's type over time, suggesting that the optimal monitoring and replacement decisions depend on current and past accounting signals. In that case, the optimal bias of the accounting report would vary with the manager's tenure.

Regardless of these possible extensions, the model we present establishes a robust association between accounting conservatism and board monitoring. This association should persist in settings that introduce other frictions or additional uses of accounting information.

Acknowledgements We thank Judson Caskey, Oliver Dürr (discussant), Ralf Ewert, Robert Göx, Mirko Heinle (discussant), Thomas Hemmer, Benjamin Hermalin, David Johnstone, Volker Laux, Shiva Sivaramakrishnan, Stefan Wielenberg (discussant), Dae-Hee Yoon (discussant); participants at the Korean

\footnotetext{
14 See, e.g., Balakrishnan et al. (2019).

15 Caskey and Laux (2017) and Bertomeu et al. (2017) make a similar assumption that board strength is associated with imposing a high cost on earnings management.
} 
Accounting Association Conference, the AAA Management Accounting Section Conference, the Eighth Accounting Research Workshop, the AAA Annual Meeting; and workshop participants at the Free University of Berlin, Rice University, the University of Sydney, the University of Texas at Austin, and the University of Tübingen for helpful comments.

Funding Open access funding provided by University of Graz.

Open Access This article is licensed under a Creative Commons Attribution 4.0 International License, which permits use, sharing, adaptation, distribution and reproduction in any medium or format, as long as you give appropriate credit to the original author(s) and the source, provide a link to the Creative Commons licence, and indicate if changes were made. The images or other third party material in this article are included in the article's Creative Commons licence, unless indicated otherwise in a credit line to the material. If material is not included in the article's Creative Commons licence and your intended use is not permitted by statutory regulation or exceeds the permitted use, you will need to obtain permission directly from the copyright holder. To view a copy of this licence, visit http://creativecommons.org/licen ses/by/4.0/.

\section{Appendix: Proofs}

Proof of Proposition 1 If $\left(q-q_{L}\right) G \leq k$, then the firm's expected period 2 profit is

$$
\Pi_{N}=q G+\operatorname{Pr}\left(y_{L}\right) \max \left\{0 ;\left(q-q_{L}\right) G-k\right\}=q G,
$$

which is independent of $f_{L}$.

If $\left(q-q_{L}\right) G>k$, then

$$
\begin{aligned}
\Pi_{N} & =q G+\operatorname{Pr}\left(y_{L}\right) \max \left\{0 ;\left(q-q_{L}\right) G-k\right\} \\
& =q G+p F(1-q) q G-\left(f_{L}-q p F\right) k \\
& >q G,
\end{aligned}
$$

which implies that $\Pi_{N}$ strictly decreases in $f_{L}$. Hence, $f_{L}=F$ is strictly optimal. The left-hand side of the condition $q-q_{L}>\frac{k}{G}$ strictly decreases in $f_{L}$ because $d q_{L} / d f_{L}>0$. Hence, if the condition holds for some $f_{L}>F$, then it holds for $f_{L}=F$. Inserting $f_{L}=F$ yields the following condition:

$$
\frac{p q(1-q)}{1-p q}>\frac{k}{G}
$$

If this condition holds, setting $f_{L}=F$ results in $\Pi_{N}>q G$ for $\left(q-q_{L}\right) G>k$.

Proof of Proposition 2 Given $y_{i}$, the board monitors if $\lambda\left(1-q_{i}\right)(q G-k)>c$. Let $c_{L}^{0} \equiv \lambda\left(1-q_{L}\right)(q G-k)$ and $c_{H}^{0} \equiv \lambda\left(1-q_{H}\right)(q G-k)$. If $c<c_{L}^{0}$, monitoring occurs at $y=y_{L}$, and if $c<c_{H}^{0}$, monitoring occurs at $y=y_{H}$. Because $q_{H}>q>q_{L}$ (as long as $F>0), \lambda\left(1-q_{L}\right)(q G-k)>\lambda\left(1-q_{H}\right)(q G-k)$, implying $c_{L}^{0}>c_{H}^{0}$. If $c<c_{H}^{0}$, monitoring occurs regardless of the signal $y$.

Given these ex post optimal monitoring strategies, the expected period 2 profit before the signal $y$ realizes is 


$$
\begin{aligned}
\Pi^{0}(c)= & q G+\operatorname{Pr}\left(y_{L}\right) \max \left\{0,\left[\lambda\left(1-q_{L}\right)(q G-k)-c\right]\right\} \\
& +\operatorname{Pr}\left(y_{H}\right) \max \left\{0,\left[\lambda\left(1-q_{H}\right)(q G-k)-c\right]\right\},
\end{aligned}
$$

which depends on $c$ as follows.

For $c<c_{H}^{0}$ (always monitoring),

$$
\begin{aligned}
\Pi_{L H}^{0}(c) & =q G+\operatorname{Pr}\left(y_{L}\right)\left[\lambda\left(1-q_{L}\right)(q G-k)-c\right]+\operatorname{Pr}\left(y_{H}\right)\left[\lambda\left(1-q_{H}\right)(q G-k)-c\right] \\
& =q G+\lambda f_{L}(1-q)(q G-k)+\lambda\left(1-f_{L}\right)(1-q)(q G-k)-c \\
& =q G+\lambda(1-q)(q G-k)-c .
\end{aligned}
$$

For $c_{H}^{0} \leq c<c_{L}^{0}$ (monitoring only at $y_{L}$ ),

$$
\begin{aligned}
\Pi_{L}^{0}(c) & =q G+\operatorname{Pr}\left(y_{L}\right)\left[\lambda\left(1-q_{L}\right)(q G-k)-c\right] \\
& =q G+\lambda f_{L}(1-q)(q G-k)-\left(f_{L}-q p F\right) c .
\end{aligned}
$$

For $c \geq c_{L}^{0}$ (never monitoring), $\Pi_{N}^{0}(c)=q G$.

Note that only $\Pi_{L}^{0}(c)$ depends on $f_{L}$ and

$$
\frac{\partial \Pi_{L}^{0}(c)}{\partial f_{L}}=\lambda(1-q)(q G-k)-c .
$$

The sign of this derivative depends on the relative values of $c$ and $\lambda(1-q)(q G-k)$. Let $c_{L H}^{0} \equiv \lambda(1-q)(q G-k)$. We know that $c_{H}^{0}<c_{L H}^{0}<c_{L}^{0}$; hence, $\frac{\partial \Pi_{L}^{0}(c)}{\partial f_{L}}>0$ for $c<c_{L H}^{0}$ and $f_{L}=1$ is optimal; $\frac{\partial \Pi_{L}^{0}(c)}{\partial f_{L}}=0$ for $c=c_{L H}^{0}$, and $\frac{\partial \Pi_{L}^{0}(c)}{\partial f_{L}}<0$ for $c>c_{L H}^{0}$ and $f_{L}=F$ is optimal. At $f_{L}=1$, the threshold $c_{H}^{0} \equiv \lambda\left(1-q_{H}\right)(q G-k)=0$ because $\left.q_{H}\right|_{f_{L}=1}=1$. Therefore, $c_{L H}^{0}<c_{L}^{0}$, hence, $f_{L}=F$ and, using $\left.q_{L}\right|_{f_{L}=F}=\frac{q-q p}{1-q p}$, we obtain $c_{L}^{0} \equiv \lambda\left(1-q_{L}\right)(q G-k)=\frac{1-q}{1-q p} \lambda(q G-k)$. If $c>\left.c_{L}^{0}\right|_{f_{L}=F}$, then no monitoring is optimal.

Finally, to establish the condition $\frac{q p(1-q)}{1-q p} \leq \frac{k}{G}$ in the proposition, note that it is the condition that the accounting system is irrelevant to the replacement decision, which is $q G-k-q_{L} G \leq 0$ evaluated at $f_{L}=F$ because this determines $\Pi_{N}^{0}$ and the adjacent $\Pi_{L}^{0}(c)$ for $c>\lambda(1-q)(q G-k)$.

Proof of Proposition 3 The proof proceeds in two steps. First, we determine the expected profits of all possible monitoring strategies and examine how the profits vary with $f_{L}$. Second, we compare the resulting expected profits of all possible monitoring strategies with their respective optimal $f_{L}$.

Step 1: The expected profits for each possible monitoring strategy are as follows.

No monitoring: 


$$
\begin{aligned}
\Pi_{N}^{R} & =q G+\operatorname{Pr}\left(y_{L}\right) \max \left\{0 ; q G-k-q_{L} G\right\} \\
& =q G+\operatorname{Pr}\left(y_{L}\right)\left(q G-k-q_{L} G\right),
\end{aligned}
$$

because the accounting system is decision-relevant. Rearranging leads to

$$
\begin{aligned}
\Pi_{N}^{R} & =q G+\left(f_{L}-q p F\right)\left(q G \frac{p F(1-q)}{f_{L}-q p F}-k\right) \\
& =q G(1+p F(1-q))-\left(f_{L}-q p F\right) k,
\end{aligned}
$$

which strictly decreases in $f_{L}$. Therefore, $f_{L}=F$ is optimal.

Always monitoring:

$$
\begin{aligned}
& \begin{aligned}
\Pi_{L H}^{R}= & q G+\operatorname{Pr}\left(y_{L}\right)\left(q G-k-q_{L} G\right) \\
& \quad+\operatorname{Pr}\left(y_{L}\right) \lambda q_{L}[G-(q G-k)]+\operatorname{Pr}\left(y_{H}\right) \lambda\left(1-q_{H}\right)(q G-k)-c
\end{aligned} \\
& =q G+\operatorname{Pr}\left(y_{L}\right)\left(q G-k-q_{L} G\right)+\lambda\left(f_{L}-p F\right) q[(1-q) G+k]+\lambda\left(1-f_{L}\right)(1-q)(q G-k)-c \\
& =q G+p F(1-q) q G-\left(f_{L}-q p F\right) k+\lambda\left[q(1-q) G(1-p F)+k\left[q-\left(q p F+1-f_{L}\right)\right]\right]-c .
\end{aligned}
$$

The first-order derivative is $\frac{\partial \Pi_{L H}^{R}}{\partial f_{L}}=-k+\lambda k<0$ for $\lambda<1$ and $f_{L}=F$ is optimal.

Monitoring only at $y_{H}$ :

$$
\begin{aligned}
\Pi_{H}^{R} & =q G+\operatorname{Pr}\left(y_{L}\right)\left(q G-k-q_{L} G\right)+\operatorname{Pr}\left(y_{H}\right)\left[\lambda\left(1-q_{H}\right)(q G-k)-c\right] \\
& =q G+p F(1-q) q G-\left(f_{L}-q p F\right) k+\lambda\left(1-f_{L}\right)(1-q)(q G-k)-\left(q p F+1-f_{L}\right) c .
\end{aligned}
$$

The first-order derivative is $\frac{\partial \Pi_{H}^{R}}{\partial f_{L}}=-k-\lambda(1-q)(q G-k)+c<0$, which holds since $c<c_{H}^{R} \equiv \lambda\left(1-q_{H}\right)(q G-k)<\lambda(1-q)(q G-k)$. Thus, $f_{L}=F$ is optimal. Monitoring only at $y_{L}$ :

$$
\begin{aligned}
\Pi_{L}^{R} & =q G+\operatorname{Pr}\left(y_{L}\right)\left(q G-k-q_{L} G\right)+\operatorname{Pr}\left(y_{L}\right)\left[\lambda q_{L}[G-(q G-k)]-c\right] \\
& =q G+p F(1-q) q G-\left(f_{L}-q p F\right) k+\left(f_{L}-p F\right) \lambda q[(1-q) G+k]-\left(f_{L}-q p F\right) c .
\end{aligned}
$$

The first-order derivative is $\frac{\partial \Pi_{L}^{R}}{\partial f_{L}}=\lambda q[(1-q) G+k]-k-c$. For low $c$, this derivative is positive and $f_{L}=1$ is optimal; otherwise, $f_{L}=F$.

To summarize, $f_{L}=F$ is optimal for all monitoring strategies except for monitoring only at $y_{L}$ and $c<\bar{c}_{L} \equiv \lambda q[(1-q) G+k]-k$.

The condition in this proposition $\frac{q p(1-q)}{1-q p}>\frac{k}{G}$ is the same as in Propositions 1 and 2. Step 2: We compare the expected profits of each monitoring strategy under optimal $f_{L}$. To shorten notation, we index $\Pi$ by the optimal $f_{L}$.

i. $\quad \Pi_{L}^{R}(1)$ and $\Pi_{L H}^{R}(F)$ :

$$
\begin{aligned}
\Delta_{L, L H}^{R} & \equiv \Pi_{L}^{R}(1)-\Pi_{L H}^{R}(F) \\
& =-(1-F) k+\lambda(1-p F) q k-(1-p q F) c-\lambda[q(1-p F)-(1-F)] k+c \\
& =-(1-F)(1-\lambda) k+q p F c .
\end{aligned}
$$


The sign of $\Delta_{L, L H}^{R}$ depends on the parameters. If $c \rightarrow 0$, then $\Delta_{L, L H}^{R}<0$ and $\Delta_{L, L H}^{R}$ increases in $c$. Thus, $\Delta_{L, L H}^{R}=0$ provides the threshold $\underline{c}$ with $\underline{c} \equiv \frac{(1-F)(1-\lambda) k}{q p F}$.

Always monitoring (with $f_{L}=F$ ) is preferable for $c \in(0, \underline{c})$ and monitoring at $y_{L}$ (with $f_{L}=1$ ) is preferable for $c \geq \underline{c}$ (although other constraints apply; see below).

ii. $\Pi_{L}^{R}(1)$ and $\Pi_{L}^{R}(F)$. The threshold for the indifference is

$\bar{c}_{L} \equiv \lambda q[(1-q) G+k]-k$.

Then, $f_{L}=1$ is optimal for $c<\bar{c}_{L}$ and $f_{L}=F$ is optimal for $c>\bar{c}_{L}$ (with arbitrary $f_{L}$ for the knife-edge case $\left.c=\bar{c}_{L}\right)$. Therefore, $c \in\left(\underline{c}, \bar{c}_{L}\right)$ is a necessary condition for $f_{L}=1$ to be optimal. This interval exists only if $\underline{c}<\bar{c}_{L}$, that is,

$\frac{(1-F)(1-\lambda) k}{q p F}<\lambda q[(1-q) G+k]-k$

or

$\lambda(1-q) \frac{q G}{k}>(1-\lambda q)+\frac{(1-F)(1-\lambda)}{q p F}$.

iii. $\quad \Pi_{L}^{R}(1)$ and $\Pi_{H}^{R}(F)$ :

$\Pi_{L}^{R}(1)=q G+p F(1-q) q G-(1-q p F) k+(1-p F) \lambda q[(1-q) G+k]-(1-q p F) c$,

$\Pi_{H}^{R}(F)=q G+p F(1-q) q G-(F-q p F) k+\lambda(1-F)(1-q)(q G-k)-(q p F+1-F) c$,

$\Delta_{L, H}^{R} \equiv \Pi_{L}^{R}(1)-\Pi_{H}^{R}(F)=(1-p) F \lambda q[(1-q) G+k]-(1-F)(1-\lambda) k-(1-2 q p) F c$.

The term $\Delta_{L, H}^{R}$ is linear in $c$ and increases if $1-2 q p<0$ and decreases otherwise. The threshold $c$ for which $\Delta_{L, H}^{R}=0$ is

$$
\begin{aligned}
& \bar{c}_{H} \equiv \frac{(1-p) F \lambda q[(1-q) G+k]-(1-F)(1-\lambda) k}{(1-2 q p) F} \\
&=\frac{1}{1-2 q p} \underbrace{\left[(1-p) \lambda q[(1-q) G+k]-\frac{1-F}{F}(1-\lambda) k\right]}_{\equiv T} .
\end{aligned}
$$

The optimality of $f_{L}=1$ requires that $c$ satisfy both conditions $c \in\left[\underline{c}, \bar{c}_{L}\right)$ and $c<\bar{c}_{H}$. Both the terms $T$ and $(1-2 q p)$ can be positive or negative. Thus, $f_{L}=1$ cannot be optimal if one term is positive and the other is negative, because then $\bar{c}_{H}<0$ and monitoring at $y_{H}$ with $f_{L}=F$ dominates monitoring at $y_{L}$ with $f_{L}=1$. A sufficient condition for $\bar{c}_{H}>0$ is if (i) $q p<0.5$ and (ii) $G$ is sufficiently large or $F$ is close to 1 . These conditions are consistent with the assumption that the accounting system is relevant to the replacement decision. 
iv. $\Pi_{L}^{R}(1)$ and $\Pi_{N}^{R}(F)$ :

$$
\begin{aligned}
\Pi_{N}^{R}(F) & =q G+\operatorname{Pr}\left(y_{L}\right)\left(q G-k-q_{L} G\right)=q G+p F(1-q) q G-(1-q p) F k, \\
\Pi_{L}^{R}(1) & =q G+p F(1-q) q G-(1-q p F) k+(1-p F) \lambda q[(1-q) G+k]-(1-q p F) c \\
\Delta_{L, N}^{R} & \equiv \Pi_{L}^{R}(1)-\Pi_{N}^{R}(F) \\
& =-(1-q p F) k+(1-p F) \lambda q[(1-q) G+k]-(1-q p F) c+(1-q p) F k \\
& =-(1-F) k+(1-p F) \lambda q[(1-q) G+k]-(1-q p F) c .
\end{aligned}
$$

The term $\Delta_{L, N}^{R}$ is linearly decreasing in $c$. The threshold $c$ for which $\Delta_{L, N}^{R}=0$ is

$\bar{c}_{N} \equiv \frac{1}{1-q p F}[(1-p F) \lambda q[(1-q) G+k]-(1-F) k]$.

This condition $c<\bar{c}_{N}$ is satisfied for large $G$ relative to $k$, for large $F$, or for high $\lambda$.

Collecting the results provides a lower bound on $c, \underline{c}>0$, and three upper bounds, $\bar{c}_{L}, \bar{c}_{H}, \bar{c}_{N}$, that must all be satisfied for conservative accounting to be optimal.

Proof of Corollary 1 To prove the existence of a non-empty set $(c, \lambda)$ for which conservative accounting is optimal, consider the relevant thresholds for $\lambda=1$ :

i. $\quad c=0$.

ii. $\quad \bar{c}_{L}=q[(1-q) G+k]-k=(1-q)(q G-k)>0$.

iii. $\bar{c}_{H}:\left.\Delta_{L H}^{R}\right|_{\lambda=1}=\underbrace{(1-p) q F[(1-q) G+k]}_{>0}-(1-2 p q) F c>0$ must be satisfied. There exist sufficiently low $c>0$, for which this inequality holds.

iv. $\quad \bar{c}_{N}:\left.\Delta_{L, N}^{R}\right|_{\lambda=1}=-(1-F) k+(1-p F) q[(1-q) G+k]-(1-q p F) c>0$ must be satisfied. This expression becomes $(1-p F)(1-q)[q G-k]+(1-p) F k-(1-q p F) c$ and is

$$
\underbrace{1-p F)(1-q)[q G-1}_{>0}
$$

greater than zero for sufficiently low $c>0$.

Define $\bar{c}=\min \left\{\bar{c}_{L}, \bar{c}_{H}, \bar{c}_{N}\right\}$. Because $\bar{c}>0$ for $\lambda=1$, the set $c \in[\underline{c}, \bar{c})$ is non-empty. To prove the result for $k=0$, we have:
i. $\quad c=0$.
ii. $\bar{c}_{L}=\lambda q(1-q) G>0$.
iii. $\bar{c}_{H}=\frac{(1-p) \lambda q(1-q) G}{1-2 q p}>0$.
iv. $\quad \bar{c}_{N}=\frac{(1-p F) \lambda q(1-q) G}{1-q p F}>0$. 
Clearly, $\bar{c}_{H}<\bar{c}_{L}$ and $\bar{c}_{N}<\bar{c}_{L}$. Therefore, $\bar{c}=\min \left\{\bar{c}_{L}, \bar{c}_{H}, \bar{c}_{N}\right\}>0$ and the set $c \in[\underline{c}, \bar{c})$ is non-empty. Due to continuity, this holds also for $\lambda$ close to 1 .

Proof of Corollary 2 Note that $c_{L H}^{0} \equiv \lambda(1-q)(q G-k)$ is not affected by $F$ if the accounting report is irrelevant to the replacement decision (Proposition 2). Otherwise, the bounds in Proposition 3 are affected by $F$ as follows: $\underline{c} \equiv \frac{(1-F)(1-\lambda) k}{q p F}$ decreases in $F$, which increases the set of $c$ that can yield conservative accounting. The bound $\bar{c}_{L} \equiv \lambda q[(1-q) G+k]-k$ does not depend on $F$ and

$$
\bar{c}_{H} \equiv \frac{1}{1-2 q p}\left[(1-p) \lambda q[(1-q) G+k]-\frac{1-F}{F}(1-\lambda) k\right]
$$

increases in $F$, which increases the set of $c$ that can yield conservative accounting. Finally,

$$
\bar{c}_{N} \equiv \frac{1}{1-q p F}[(1-p F) \lambda q[(1-q) G+k]-(1-F) k]
$$

depends on $F$ in a more complex fashion. The sign of the first derivative of $\bar{c}_{N}$ with respect to $F$ is equal to the sign of $(1-q p) k-p(1-q) \lambda q[(1-q) G+k]$.

Since $\bar{c}_{L}>0$ implies $\lambda q[(1-q) G+k]>k$, the first derivative is positive if $p$ is sufficiently small.

\section{References}

Ahmed, A. H., \& Duellman, S. (2007). Accounting conservatism and board of director characteristics: An empirical analysis. Journal of Accounting and Economics, 43, 411-437.

Armstrong, C. S., Guay, W. R., \& Weber, J. P. (2010). The role of information and financial reporting in corporate governance and contracting. Journal of Accounting and Economics, 50, 179-234.

Arya, A., Glover, J., \& Sunder, S. (1998). Earnings management and the revelation principle. Review of Accounting Studies, 3, 7-34.

Balakrishnan, R., Drymiotes, G., \& Sivaramakrishnan, K. (2019). The effects of biasing performance measurement systems on incentives and retention decisions. Contemporary Accounting Research, 36, 1098-1121.

Barker, R. (2015). Conservatism, prudence and the IASB's conceptual framework. Accounting and Business Research, 45, 514-538.

Beekes, W., Pope, P., \& Young, S. (2004). The link between earnings timeliness, earnings conservatism and board composition: Evidence from the UK. Corporate Governance: An International Review, 12, 47-59.

Bertomeu, J., Darrough, M., \& Xue, W. (2017). Optimal conservatism with earnings manipulation. Contemporary Accounting Research, 34, 252-284.

Beyer, A., Guttman, I., \& Marinovic, I. (2014). Optimal contracts with performance manipulation. Journal of Accounting Research, 52, 817-847.

Brown, P., Beekes, W., \& Verhoeven, P. (2011). Corporate governance, accounting and finance: A review. Accounting and Finance, 51, 96-172.

Bushman, R. M., \& Smith, A. J. (2001). Financial accounting information and corporate governance. Journal of Accounting and Economics, 32, 237-333.

Caskey, J., \& Hughes, J. (2012). Assessing the impact of alternative fair value measures on the efficiency of project selection and continuation. The Accounting Review, 87, 483-512. 
Caskey, J., \& Laux, V. (2017). Corporate governance, accounting conservatism, and manipulation. Management Science, 63, 424-437.

Chaigneau, P., \& Sahuguet, N. (2019). CEO turnover: Performance measurement and monitoring. Working paper, Queen's University.

Christensen, J. A., \& Demski, J. S. (2003). Accounting theory-An information content perspective. New York: McGraw-Hill.

Crémer, J. (1995). Arm's length relationships. Quarterly Journal of Economics, 110, 275-295.

Drymiotes, G., \& Sivaramakrishnan, K. (2012). Board monitoring, consulting, and reward structures. Contemporary Accounting Research, 29, 453-486.

Fan, Q., \& Zhang, X.-J. (2012). Accounting conservatism, aggregation, and information quality. Contemporary Accounting Research, 29, 38-56.

García Lara, J. M., García Osma, B., \& Penalva, F. (2007). Board of directors' characteristics and conditional accounting conservatism: Spanish evidence. European Accounting Review, 16, 727-755.

García Lara, J. M., García Osma, B., \& Penalva, F. (2009). Accounting conservatism and corporate governance. Review of Accounting Studies, 14, 161-201.

Gigler, F., \& Hemmer, T. (2001). Conservatism, optimal disclosure policy, and the timeliness of financial reports. The Accounting Review, 76, 471-493.

Gigler, F., Kanodia, C., Sapra, H., \& Venugopalan, R. (2009). Accounting conservatism and the efficiency of debt contracts. Journal of Accounting Research, 47, 767-797.

Guo, L., \& Masulis, R. W. (2015). Board structure and monitoring: new evidence from CEO turnovers. Review of Financial Studies, 28, 2770-2811.

Hermalin, B. (2005). Trends in corporate governance. Journal of Finance, 60, 2351-2384.

Hermalin, B., \& Weisbach, M. (1998). Endogenously chosen boards of directors and their monitoring of the CEO. American Economic Review, 88, 96-118.

Jensen, M. C., \& Meckling, W. H. (1976). Theory of the firm: managerial behavior, agency costs and ownership structure. Journal of Financial Economics, 3, 305-360.

Krishnan, G. V., \& Visvanathan, G. (2008). Does the SOX definition of an accounting expert matter? The association between Audit Committee Directors' Accounting Expertise and Accounting Conservatism. Contemporary Accounting Research, 25, 827-857.

Larcker, D. F., Richardson, S. A., \& Tuna, İ. (2007). Corporate governance, accounting outcomes, and organizational performance. The Accounting Review, 82, 963-1008.

Larcker, D., \& Tayan, B. (2016). Corporate governance matters (2nd ed.). Upper Saddle River: Pearson.

Laux, V. (2008). Board independence and CEO turnover. Journal of Accounting Research, 46, 137-171.

Laux, V. (2013). Corporate governance, board oversight, and CEO turnover. Foundations and Trends in Accounting, 8, 1-73.

Li, H. (2001). A theory of conservatism. Journal of Political Economy, 109, 617-636.

Li, J. (2013). Accounting conservatism and debt contracts: Efficient liquidation and covenant renegotiation. Contemporary Accounting Research, 30, 1082-1098.

Lobo, G. L., \& Zhou, J. (2006). Did conservatism in financial reporting increase after the SarbanesOxley Act? Initial evidence. Accounting Horizons, 20, 57-74.

Milgrom, P., \& Roberts, J. (1992). Economics, organization, and management. Englewood Cliffs: Prentice Hall.

Penalva, F., \& Wagenhofer, A. (2019). Conservatism in debt contracting: theory and empirical evidence. Accounting and Business Research, 49, 619-647.

Ramalingegowda, S., \& Yu, Y. (2012). Institutional ownership and conservatism. Journal of Accounting and Economics, 53, 98-114.

Smith, M. J. (2007). Accounting conservatism and real options. Journal of Accounting, Auditing and Finance, 22, 449-467.

Tian, J. J. (2014). Board monitoring and endogenous information asymmetry. Contemporary Accounting Research, 31, 136-151.

Watts, R. L. (2003). Conservatism in accounting part I: Explanations and implications. Accounting Horizons, 17, 207-221.

Publisher's Note Springer Nature remains neutral with regard to jurisdictional claims in published maps and institutional affiliations. 
Yanmin Gao is an associate professor of accounting at Thompson Rivers University. She obtained her $\mathrm{Ph} . \mathrm{D}$. in accounting from the University of British Columbia and an M.A. in economics from the University of Windsor. Her research studies a range of issues of interest to academics, policy makers and practitioners, including accounting fraud, corporate governance, corporate social responsibility, and social media.

Alfred Wagenhofer is a professor of accounting, head of the Institute of Accounting and Control and director of the Center for Accounting Research at the University of Graz. His research interests include financial and management accounting issues, particularly conservatism, earnings management and disclosure, as well as management incentives and performance measurement, corporate governance and enforcement. 